\title{
ОПОРА ДЛЯ ПОГЛОШЕНИЯ КОЛЕБАНИЙ ГЛАВНОГО ВАЛА ЩВЕЙНОЙ МАШИНЫ
}

\author{
Джкраев Анвар Джураевич \\ д.m.н., профессор \\ Ташкентского института текстильной и лёгкой промышленности, \\ 2. Ташкент, Республика Узбекистан \\ Мансурова Муниса Анваровна \\ д.m.н., профессор \\ Ташкентского института текстильной и лёгкой промышленности, \\ 2. Ташкент, Республика Узбекистан \\ Курбанова Ирода Ихтиёровна \\ докторант \\ Бухарский инженерно-технологический институт, \\ г.Бухара, Республика Узбекистан
}

Аннотация: В этой статье представлена информация о снижение вибрации и шума главного вала и за счёт этого повешение надёжности, производительности швейной машины. Поставленная задача решается путем амортизации колебаний и шума главного вала швейный машин, совершенствованием конструкции подшипниковых опор.

Abstract: This article presents information about reducing vibration and noise of the main shaft and thereby increasing the reliability and productivity of the sewing machine. The task is solved by damping the vibrations and noise of the main shaft of sewing machines, improving the design of bearing supports.

Ключевые слова: механизм, подщипник, качения, вал, деталь, ось, колебаний, опора, упруга, корпус, втулка, кольцо, долговечность, эффективность.

Keywords: mechanism, bearing, rolling, shaft, part, axis, oscillation, support, elastic, housing, sleeve, ring, durability, efficiency.

\section{Введение.}

Статья относится к общему машиностроению и может быть использовано в швейных машинах.

Известны опоры, в которых подшипник сопрягается непосредственно с корпусом, и присоединительными поверхностями подшипника качения к корпусу машины является наружный диаметр и ширина колец $[1,2]$.

Недостатком существующих опор в составе любых механизмов и машин является непосредственная передача колебания вращающихся валов в корпусах машин и механизмов на сами корпуса, что приводит к увеличению виброшума соответствующих машин, а также быстрому выходу из строя подшипниковых опор.

Известна конструкция опоры вала, содержащая корпус со смонтированным в нем подшипником и размещенной между наружной поверхностью и корпусом упругий элемент овальной формы [3].

Недостатком этой конструкции является её сложность и большие затраты в изготовлении. Кроме того, данная конструкция теряет эффект поглощения колебаний вала при высоких скоростных режимах и больших моментов инерций валов.

В следующей известной конструкции опоры для поглощения колебаний вращающихся валов содержится корпус со смонтированным в нем подшипником и размещенной между его наружной поверхностью и корпусом резиновую втулку круглого сечения. При этом ось отверстия втулки смещена относительно её центральной оси (эксцентрично) [4].

Недостатком данной конструкции также является низкий эффект поглощения вибраций вращающихся валов при высоких скоростных режимах валов. Следует отметить, что одним из недостатков опор валов включающие подшипников качения является значительные силы на корпус машины из-за малой площади контакта наружных колец подшипников с корпусом машины [5].

В другой известной конструкции опоры для поглошения колебаний вращающихся валов, содержащая корпус со смонтированным в нем подшипников и размещенным по его наружной поверхности упругим элементом, выполненный в виде усечённых конических втулок, установленных таким образом, что малое основание втулки направлено к наружной поверхности корпуса, а основание большого диаметра - в сторону внутренней поверхности корпуса [6].

Недостатком данной конструкции является отсутствие возможности ликвидации осевых сил реакции при несимметричном нагружение вала. 
В известном вращающемся главном валу швейной машины класса ПМЗ 206, 266 и других классов, содержащие три подшипниковые опоры (прототип). Движение от двигателя передаётся главному валу ременной передачей. Механизмы иглы, перемещения материалов и петлителя получают движение от главного вала. За счёт переменности моментов инерций соответствующих звеныв (шатуна) этих механизмов главный вал получает переменные нагрузки, как в вертикальном, так и в осевом направлениях [7]. Следует отметить, что осевом главные валы имеющие три подшипниковые опоры имеются и ряде других классах швейных машин [8, 9].

Основным недостатком подшипниковых опор главного вала швейных машин является вибрация, шум при высоких скоростных режимах (5000-8000 об/мин) за счёт неуравновешенных масс, воздействия переменных инерционных нагрузок и отсутствия амортизации колебаний вала.

Цель статьи является снижение вибрации и шума главного вала и за счёт этого повешение надёжности, производительности швейной машины. Поставленная задача решается путем амортизации колебаний и шума главного вала швейный машины, совершенствованием конструкции подшипниковых опор.

Сущность конструкции заключается в том, что опора для поглощения колебаний главного вала швейный машины содержит корпус и смонтированные в нем трёх подшипников и размешенные между их наружными поверхностями и корпуса упругие резиновые втулки. При этом толщина упругой втулки средней опоры выбран большим, чем толщина упругих втулок двух крайних подшипников, при чем толщина упругой втулки второго крайнего подшипника выбрана равным среднему значению толщин двух других упругих втулок подшипников. Упругие резиновые втулки по наружной поверхности выполнены выпуклыми. При этом радиусы кривизны выпуклостей каждых упругих втулок выбраны равными наружному радиусу соответствующих втулок. Выполнение толщины упругой втулки среднего подшипника большого размера позволяет большую деформацию, чем крайних упругих втулок подшипников, обеспечивает поглощение основной части вертикальных колебаний главного вала. Выполнение наружных поверхностей упругих втулок (выпуклым) обеспечивает центрирование деформаций, приводит к увеличению надёжности работы главного вала швейный машины.

Выбор толщины упругой втулки второго крайнего подшипника равным среднего значения толщин двух остальных упругих втулок ликвидирует угловое перемещение оси главного вала. Рекомендуемая опора для поглощения колебаний главного вала позволяет значительно уменьшить колебания и шум главного вала, повышает надёжность работы, появляется возможность увеличения скоростного режима машины. 


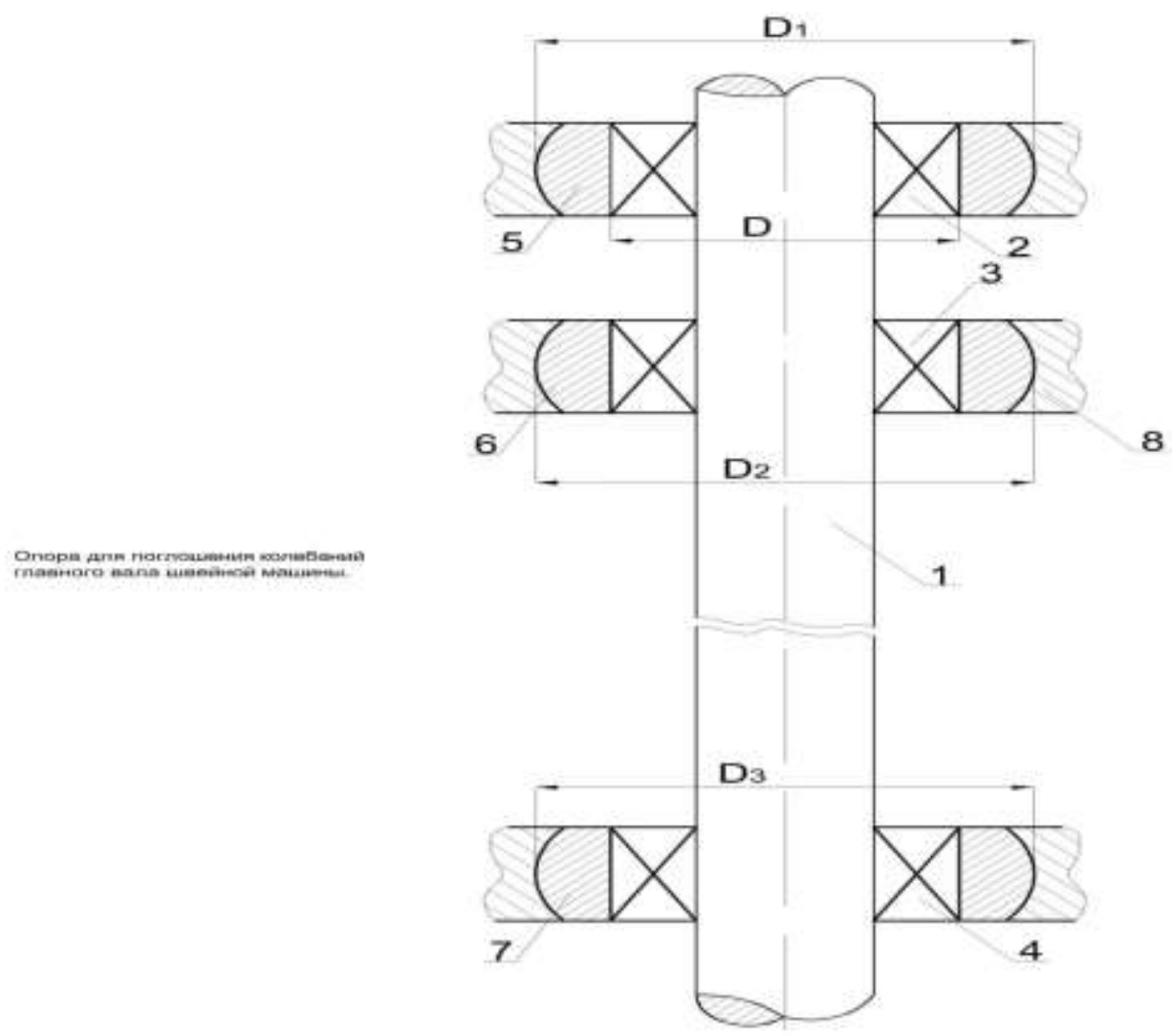

Puc

.1.1. Опора для поглощения колебаний главного вала швейной машин.

Конструкция поясняется чертежом, где на фиг 1.1 - приводится общая схема главного вала с тремя упругими подшипниковыми опорами в продольном разрезе.

\section{Полученные результаты и обсуждение.}

Опора для поглощения колебаний главного вала швейной машины содержит главный вал 1, установленные на нем подшипники $2,3,4$. Между наружными поверхностями подшипников 2, 3, 4 и корпусом 8 установлены упругие резиновые втулки $5,6,7$. При этом толщина $h_{2}$ упругой втулки выбрано большей, чем толщины $h_{1}$ и $h_{3}$ двух упругих втулок 5 и 7.

Толщина $h_{3}$ упругой втулки 7 выбрана равным среднему значению толщин $h_{1}$ и $h_{2}$ упругих втулок 5 и 6:

$$
\begin{aligned}
& h_{1}=\frac{D_{1}-D}{2} ; h_{2}=\frac{D_{2}-D}{2} ; h_{2}=\frac{D_{a}-D}{2} ; \\
& h_{a}=\frac{h_{1}+h_{3}}{2} ;
\end{aligned}
$$

$h_{2}>h_{1}$

где $h_{1} h_{2} h_{3}$ - толщины упругих резиновых втулок $5,6,7$;

$D_{2} D_{1}, D_{2}, D_{3}$ - соответственно наружный диаметр подшипников 2, 3, 4 диаметры наружных окружностей упругих резиновых втулок $5,6,7$.

Упругие резиновые втулки 5, 6, 7 по наружным поверхностям выполнены выпуклыми. Радиусы выпуклостей выбраны равным соответствующих радиусов наружных поверхностей упругих резиновых втулок 5,6,7, при этом: 


$$
R_{\mathrm{B} 1}=\frac{D_{1}}{2} ; R_{\mathrm{B} 2}=\frac{D_{2}}{2} ; R_{\mathrm{Ba}}=\frac{D_{3}}{2} ;
$$

где $R_{\mathrm{B} 1_{2}} R_{\mathrm{B} 2} R_{\mathrm{B} 3}$ - соответственно радиусы выпуклостей упругих резиновых втулок $5,6,7$ по наружным их поверхностям.

В процессе работы на вращающийся главный вал действуют следующие силы: движущий момент от приводной ременной передачи с правого конца вала 1; силы тяжести, переменные инерционные силы; сопротивления от механизмов иглы, петлителя, перемещения материалов (на рис. не показан), силы трения, технологические нагрузки и другие. Эти силы будут действовать циклически на корпус 8 через подшипники 2 , 3,4 . Наличие упругих резиновых втулок 5, 6, 7 значительно уменьшают действия этих сил на корпус 8 . При этом величина изгиба вала 1 за счёт деформаций упругих резиновых втулок 5, 6, 7 практически снижается до нуля. Выполнение упругих резиновых втулок 5, 6, 7 с различной толщиной позволяют постепенное поглощение колебаний вала 8 за счёт их деформаций. При этом нагрузки со стороны вращающегося главного вала 8 швейной машины будут распределяться и поглощаться упругими резиновыми втулками 5, 6, 7 ( при трёх опорных валах). За счёт меньшей жёсткости упругой резиновой опоры 6 (большой толщины $h_{2}$ ) среднего подшипника 3 происходить наибольщая деформация упругой втулки 6, что проводить к поглощению основной части колебаний вала 8 . Остальные высокочастотная часть колебаний вала 8 поглошается соответствующими деформациями упругих резиновых втулок 5 и 7 . Выполнение толщины $h_{3}$ упругой резиновой втулки равным среднему значению толщин $h_{1}$ и $h_{2}$ приводит к незначительным угловым перемещениям главного вала 8 . При этом выполнение наружных поверхностей упругих резиновых втулок 5, 6, 7 выпуклыми с соответствующими радиусами кривизны $R_{1} R_{2}$ и $R_{3}$ обеспечивают центрирование их деформаций и позволяет эффективное поглощение колебаний главного вала 8.

Соответственно выбирая необходимые значения жёсткостей, толщина и других размеров, марки резиновых втулок 5, 6, 7 подшипников 2, 3, 4 можно значительно уменьшит нагруженность главного вала и соответственно повышению скоростных режимов.

\section{Выводы.}

Конструкция позволяет эффективные поглощение колебаний главного вала швейной машины при высоких скоростных режимов сшивания материалов, приводящих к надёжной работе при высокой производительности.

\section{Использованная литература}

1. Якушев А.И., Воронцов Л.Н., Федотов Н.М. Взаимозаменяемость,стандартизация и технические измерения.-М.: Машиностроение, 1986.-235 с.

2. $\quad$ Тожибоев Р., Джураев А.Машина деталлари.-Т.: Ўқитувчи, 1999.-225 с.

3. Авторское свидетельство.№870784, МПК F 16 С 27/02,1981.

4. Патент РУз. IDP 04489. Опора для поглощения колебаний вращающихся валов. 7 F 16 C 17/02, 27/02.-Т.:2000.Бюлл. №5.

5. Сулаймонов И.Машина деталлари (учебнык). Изд.-Т.: Ўқитувчи, 1981.-250-252 c.

6. В.П.Полухин, А.В.Рейбарх. Швейные машины цепного стежка.М. "Лёгкая индустрия" 1976, 352

c.

7. Kurbanova I.I. Journal of Science and Technology Development- Bukhara-2017/2. Improvement of needle mechanics of sewing machines.

8. Курбанова И.И. Теоретические и экспериментальные исследования расчета пряжи и времени, затрачиваемого на прядение на швейной машине. EPRA International Journal of Research and Development 2021 г.

9. Курбанова И.И. Динамический анализ совершенствования игольного механизма швейных машин. III Международная научная конференция «МИП: Машиностроение-III-2021: Модернизация, инновации, прогресс: передовые технологии в материаловедении, машиностроении и автоматизации», 2021 г. 